\title{
Evaluation of the prevalence of waterpipe tobacco smoking and its related factors in Tehran, Islamic Republic of Iran
}

Zahra Hessami ${ }^{1}$, Mohammed R. Masjedi, ${ }^{2}$ Reza Ghahremani, ${ }^{3}$ Mehdi Kazempour ${ }^{4}$ and Habib Emami ${ }^{7}$

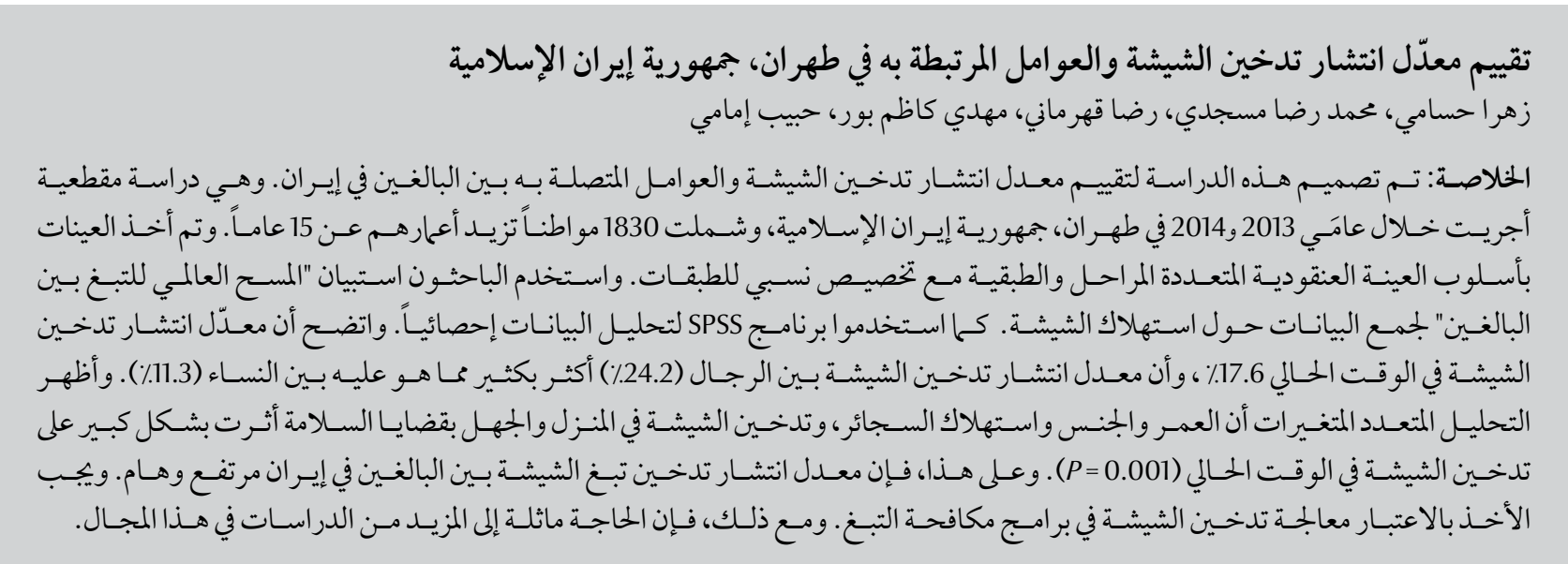

ABSTRACT This study is designed to evaluate the prevalence of waterpipe tobacco smoking and its related factors among Iranian adults. This is a cross-sectional study carried out during 2013/14 in Tehran, Islamic Republic of Iran, among 1830 citizens aged over 15 years. Sampling was through Stratified multistage cluster sampling with proportional allocation within strata. Global Adult Tobacco Survey (GATS) questionnaire for waterpipe consumption was used for data gathering. Data were statistically analyzed by SPSS software. The prevalence of current waterpipe tobacco smoking was $17.6 \%$.Waterpipe use prevalence in men was significantly more than women (24.2\% vs. $11.3 \%)$. Multivariate analysis showed that age, sex, cigarette consumption, waterpipe consumption at home and ignorance of safety issues significantly influenced current waterpipe smoking $(P=0.001)$. Thus, prevalence of waterpipe smoking in Iranian adults is high and significant. Tackling waterpipe smoking should be considered in tobacco control programmes. However, further studies in this field are needed.

\section{Évaluation de la prévalence de la consommation de tabac par pipe à eau et de ses facteurs associés à} Téhéran, République islamique d'Iran

RÉSUMÉ La présente étude est conçue pour estimer la prévalence de la consommation de tabac par pipe à eau et de ses facteurs associés dans la population adulte iranienne. Il s'agit d'une étude transversale, conduite entre 2013 et 2014 à Téhéran, en République islamique d'Iran, parmi 1830 citoyens âgés de plus de 15 ans. La technique utilisée était celle de l'échantillonnage en grappe stratifié à plusieurs niveaux avec allocation proportionnelle dans les strates. Le questionnaire de l'enquête mondiale sur le tabagisme chez les adultes pour la consommation de tabac par pipe à eau a été utilisé afin de collecter les données. Celles-ci ont été analysées sur le plan statistique à l'aide du logiciel SPSS. La prévalence de la consommation de tabac par pipe à eau au moment de l'étude était de $17,6 \%$, et était plus importante chez les hommes que chez les femmes ( $24,2 \%$ contre $11,3 \%$ ). L'analyse multivariée a montré que l'âge, le sexe, la consommation de cigarettes, la consommation de pipe à eau à la maison et l'ignorance des questions de sécurité influençaient de façon significative la consommation de tabac par pipe à eau $(p=0,001)$. Par conséquent, la prévalence de la consommation de tabac par pipe à eau est élevée et significative parmi les adultes iraniens. La question de la consommation de tabac par pipe à eau devrait être traitée dans le cadre des programmes de lutte antitabac. Néanmoins, d'autres études dans ce domaine sont requises. 


\section{Introduction}

The waterpipe is an old method of tobacco smoking, its origin tracing back 4 centuries in the Middle East, but its use extends around the world (1). Waterpipe smoke contains many toxicants and carcinogens. There is evidence of waterpipe smoking-related conditions such as lung and cardiovascular diseases, complications of pregnancy, cancers, oral dysplasia and infertility (2-4). Despite the harmful effects, the prevalence of waterpipe smoking is increasing around the world, especially among the young (5). The main reason for this increase is that users perceive the waterpipe as a safer and less addictive alternative to other tobacco products $(6,7)$.

Waterpipe smoking is now considered by the WHO as a general health problem (8). Waterpipe smoking prevalence should therefore be considered as a factor in tobacco control programmes (9-11).

There have been fewer studies on waterpipe smoking than on cigarette consumption. The Islamic Republic of Iran is a country in which waterpipe smoking has a historical origin. In recent years, the waterpipe use pattern has changed in the Iranian population. It seems that, compared with the past, waterpipe smoking is currently more commonly seen among the young and among women. According to a study from 2010, traditional restaurants were the first places where students experience tobacco, and the waterpipe was the first type of tobacco they used (12). The prevalence of tobacco smoking is $15 \%$ (13), although there are currently no comprehensive and representative studies on the prevalence of waterpipe smoking. The majority of studies on tobacco use study cigarette consumption rather than waterpipe smoking, and previous studies on waterpipe smoking have mainly been done on special groups. In order to better understand waterpipe consumption trends, find better ways to fight against it and design prevention and control programmes, we carried out this study to evaluate the prevalence of waterpipe smoking and its related factors in a broad population of Iranian adults.

\section{Methods}

This cross-sectional study was conducted in November and December 2014 on participants aged 15 years and over in Tehran.

Sample size was calculated using the following formula, assuming a 95\% confidence interval $(Z 1-\alpha / 2=1.96)$, precision of $0.03(d=0.03), P=0.5$.

Thus:

$$
\mathrm{N}=0.5 \times 0.5 \times\left(1.96^{2}\right) / 0.03^{2}=1067
$$

Considering a design effect of 1.5 and a missing rate of $15 \%$, the total sample size was calculated as 1840 .

Stratified cluster random sampling with proportional allocation within strata was used in this study. Tehran has 22 municipality districts in which there are several zones. A municipality district was selected randomly from each geographical area of Tehran (north, south, east, west and centre). The following districts were selected: District No. 1 in the north, District No. 20 in the south, District No. 14 in the east, District No. 21 in the west and District No. 12 in the centre. After this, 2 zones were chosen randomly from each district. Each zone included 1 health centre with several health care workers. We chose 2 health care workers from each zone based on their experience in research programmes and volunteering. After informing them about the aims of the project, they were trained for data gathering.

Data collection was conducted by the healthcare workers under the supervision of the Tobacco Prevention and Control Research Centre. Five data collection teams were involved in this study, each consisting of a supervisor and 2 interviewers. A house in each zone was selected randomly, and in a clockwise direction all the surrounding homes were selected for sampling. After explaining the objectives of the project and obtaining consent, participants aged $\geq 15$ years were interviewed.

Data gathering was carried out using the standard Global Adult Tobacco Survey (GATS) questionnaire (14). This has several sections and is designed to evaluate the tobacco smoking habits of adults based on each country's characteristics. One section is dedicated to waterpipe smoking habits. We used the questions of this section in addition to some optional questions about waterpipe smoking. After inserting some adaptations for the Islamic Republic of Iran, as follows: first, the questionnaire was translated to Farsi by a native speaker, fluent in English and familiar with health issues (forward translation). Second, the content was assessed by an expert team and after that an English language native translated it into English (back translation). Then the 2 English versions were compared. Finally, 4 waterpipe smokers were asked to give their comments on the questionnaire to ensure clarity, and the final version was used in the study.

Our study variables consist of current waterpipe smoking as the dependent variable, and sex, age, education level, marital status, cigarette smoking habits, knowledge about the harmful effects of waterpipe smoking and bans on waterpipe smoking in the home as independent variables.

Current waterpipe smokers are those who use the waterpipe daily or, if less frequently, have smoked waterpipe during the past 30 days. Another group, the lifelong waterpipe smokers, comprises those who have experienced waterpipe smoking, even as little as 1 puff, during their life. Non-waterpipe smokers are those who have never smoked a waterpipe in their life. All 3 groups could be cigarette smokers or not. 
All data were analysed using SPSS, version 18. Qualitative variables were reported as percentages and quantitative variables as mean and standard deviation. Current and lifetime waterpipe smoking prevalence was calculated. For evaluating the association between selected variables and current waterpipe smoking, logistic regression was used. Unadjusted and adjusted odds ratios were calculated. In all analyses, $P \leq 0.05$ was considered statistically significant.

\section{Results}

A total of 1830 participants aged $\geq 15$ years took part in this study, of whom 883 (48.3\%) were male. The mean age was 33.7 (standard deviation 1.37) years. The number of current waterpipe smokers was 316 [17.6\%; 95\% confidence interval (CI): 15.8-19.2] and 409 (22.6\%; 95\% CI: 20.6-24.5) were in the lifelong waterpipe smoker category. Sex was a significant factor: 212 of the male participants (24.0\%; 95\% CI: 21.3-27.0) were current waterpipe users compared with 104 females (11.35\%; 95\% CI: 9.2-13.3) ( $P$ $<0.001$ ) (Table 1).

There was also a significant difference in regard to education level: the lowest waterpipe smoking rate was seen among those with a university education $(97 ; 30.6 \%)(P=0.025)$. We found that 120 current waterpipe smokers (38.0\%; 95\% CI: 32.6-43.3) were also current cigarette smokers. The mean age of first waterpipe use was 21.3 (standard deviation 6.3) years. Full demographic characteristics of current waterpipe smokers are shown in Table 1.

Simple and multiple logistic regression were used to evaluate the association between selected variables and current waterpipe smoking (Table 2). In the multivariate analysis, being male [odds ratio $(\mathrm{OR})=3.19$, 95\% CI: 2.17-4.68], current cigarette smoking $(\mathrm{OR}=3.13,95 \% \mathrm{CI}: 2.02-4.87)$, and misperceptions about the safety of waterpipe smoking $(\mathrm{OR}=3.58,95 \%$ CI: $1.73-7.42$ ) were positively associated with current use of a waterpipe. Bans on waterpipe smoking in the home were negatively associated with current waterpipe smoking $(\mathrm{OR}=0.1$ 95\% CI: 0.06-0.20).

We found that $58.8 \%$ of waterpipe smokers and $88.5 \%$ of non-waterpipe smokers believed that waterpipe smoking could cause serious disease. Less than a third of waterpipe smokers (80; $25.3 \%$ ) believed that waterpipe smoking could cause stroke compared with more than half of the non-smokers (675; 62.0\%). Furthermore, 36.7\% of waterpipe smokers thought that waterpipe smoking could lead to heart attack; $17 \%$ did not believed this, and $39 \%$ had no information. Additionally, 43d.9\% of waterpipe smokers believed that waterpipe smoking could cause lung cancer compares with $78.5 \%$ of non-smokers. Nearly three-quarters (70.6\%) of waterpipe smokers considered it to be addictive, compared with
$87.0 \%$ of non-smokers. Half (50.0\%) of non-waterpipe smokers thought that the waterpipe was more addictive than cigarette smoking versus only $39.5 \%$ of waterpipe smokers; $18.8 \%$ of waterpipe smokers considered the waterpipe less addictive than cigarette smoking, but only $13.5 \%$ of non-waterpipe smokers agreed $(P<0.001)$.

\section{Discussion}

The study examined waterpipe smoking prevalence in Iranian adults aged 15 years and older. It is unique in this field in the Islamic Republic of Iran. It uses a standard questionnaire and is comparable to other similar studies. Almost half of the participants had the experience of waterpipe smoking at some point in their lives, with current smokers accounting for $17.6 \%$. According to the results of a study done in the Islamic Republic of Iran, $1 \%$ of participants were daily waterpipe smokers (15). The

\begin{tabular}{lccc}
\hline Table 1. Demographic characteristics of current waterpipe smokers $(\boldsymbol{n}=316)$ aged \\
$\begin{array}{l}\text { 15 years, Tehran, 2014 } \\
\text { Characteristic }\end{array}$ & No. & Paterpipe smokers & P-value \\
& & & \\
Sex & 212 & 67.1 & $<0.001$ \\
$\quad$ Male & 104 & 32.9 & \\
Female & & & \\
Age (years) & 21 & 6.6 & \\
15-17 & 95 & 30.0 & \\
18-24 & 153 & 48.4 & \\
25-39 & 34 & 10.7 & \\
40-54 & 13 & 4.3 & \\
$\geq$ 55 & & & \\
Marital status & 162 & 51.4 & \\
Married & 141 & 44.6 & \\
Single & 13 & 4.0 & \\
Divorced/widowed & & & \\
Education & 10 & 3.2 & \\
Illiterate & 90 & 28.5 & \\
Below high school diploma & 119 & 37.7 & \\
High school diploma & 97 & 30.6 & \\
University & & & \\
\hline
\end{tabular}

Afew values missing in some categories. 
prevalence of current water pipe smoking among women in Tehran was 6.3\% in 2012 (16). Another study carried out in all provinces of the country found a prevalence of $2.7 \%$ for waterpipe smoking (17). In a study in a random sample of university students at 2 major universities in the south of the country, respondents' lifetime waterpipe smoking rate was $42.5 \%$ and was $18.7 \%$ in the last 30 days (18). Prevalence of waterpipe smoking in college students in Tabriz was $8.5 \%$ ( $\geq 1$ time per month) (19).

Like cigarette smoking, waterpipe smoking rates differed significantly between the sexes, being twice as high in males as in females. Our findings in this respect are similar to those of studies from Viet Nam (6.4\%) and Lebanon (15.0\%) (20,21). A 2010 study in the Islamic Republic of Iran also showed that cigarette smoking and waterpipe smoking were more prevalent among men (15).

However, the difference between males and females in smoking rates is lower for waterpipe smoking than for cigarette smoking. According to the latest Iranian statistics on cigarette smoking, the rate for males is about 10 times higher than for females (13). This may be due to greater rates of risk-taking behaviour among males and more attention of females to their health. However, the tendency to waterpipe smoking can be seen among females in many communities due to the belief that waterpipe use is less hazardous than cigarette smoking. Also, in the Iranian community some cultural and religious barriers exist against cigarette smoking for females. In a study done among American university students the rate of waterpipe smoking among men (22\%) was significantly greater than among women (11\%) (22). However, underreporting by females should not be overlooked.

In agreement with previous studies (15-19), our results show that the waterpipe tobacco smoking rate among Iranians is increasing each year, and this could be due to the failure of Iranian tobacco control programmes in the field of waterpipe smoking. It should be noted that due to the differences in the methods and sample sizes, these studies are not fully comparable; however, the increasing trend of consumption is inferable.

Many people believe that waterpipe smoking is less harmful than cigarette smoking $(7,23)$. These results show that being informed about causal relationships between waterpipe smoking and serious diseases significantly reduces the likelihood of becoming a current user. Our results also show that current

\begin{tabular}{|c|c|c|c|}
\hline Characteristic & $\begin{array}{c}\text { Waterpipe } \\
\text { smokers (\%) }\end{array}$ & $\begin{array}{c}\text { Crude OR } \\
(95 \% \mathrm{Cl})\end{array}$ & $\begin{array}{c}\text { Adjusted OR } \\
(95 \% \mathrm{Cl})\end{array}$ \\
\hline \multicolumn{4}{|l|}{ Sex } \\
\hline Female & 11.0 & 1.00 & 1.00 \\
\hline Male & 24.0 & $2.51(1.94-3.24)$ & $3.19(2.17-4.68)$ \\
\hline \multicolumn{4}{|l|}{ Age (years) } \\
\hline $15-17$ & 13.6 & 1.00 & 1.00 \\
\hline $18-24$ & 31.7 & $2.80(1.69-9.7)$ & $1.50(0.73-3.1)$ \\
\hline $25-39$ & 18.9 & $1.42(0.88-2.31)$ & $0.94(0.43-2.03)$ \\
\hline $40-54$ & 10.7 & $0.75(0.40-1.29)$ & $0.31(0.12-0.78)$ \\
\hline$\geq 55$ & 4.0 & $0.25(0.10-0.61)$ & $0.04(0.01-0.13)$ \\
\hline \multicolumn{4}{|c|}{ Cigarette smoking status } \\
\hline Non-smoker & 7.9 & 1.00 & 1.00 \\
\hline Current smoker & 38.0 & $5.2(3.89-6.95)$ & $3.13(2.02-4.87)$ \\
\hline \multicolumn{4}{|c|}{ Waterpipe smoking at home } \\
\hline Allowed & 63.2 & 1.00 & 1.00 \\
\hline Not allowed & 11.3 & $0.06(0.04-0.09)$ & $0.10(0.06-0.20)$ \\
\hline \multicolumn{4}{|c|}{ Waterpipe smoking permitted in all rooms } \\
\hline No & 27.3 & 1.00 & 1.00 \\
\hline Yes & 50.1 & $7.77(5.87-1.28)$ & $2.24(1.42-3.54)$ \\
\hline \multicolumn{4}{|c|}{ Believe waterpipe smoking causes serious illness } \\
\hline Yes & 58.8 & 1.00 & 1.00 \\
\hline No & 20.6 & $5.28(3.67-7.58)$ & $3.58(1.73-7.42)$ \\
\hline
\end{tabular}

$O R=$ odds ratio $; C I=$ confidence interval . 
users significantly believe that waterpipe smoking has no effect on lung cancer, stroke or heart attack. According to a study on adolescents, belief in the harms of waterpipe smoking decreased the likelihood of consumption (24).

Therefore, it seems that promoting general knowledge by holding educational programmes could lead to a reduction in waterpipe smoking. Another factor that affects waterpipe smoking is cigarette smoking. Our results show that cigarette smoking, either past or current, increases the likelihood of waterpipe smoking. This relationship was seen even after the omission of confounders. Waterpipe use was nearly 2 times greater in cigarette smokers than in non-smokers. This result is similar to many other studies, including the study of Jawad, Lee and Millett in which cigarette consumption increased the likelihood of waterpipe consumption by a factor of 3 (25), also in a Turkish study cigarette consumption was a factor that increased the likelihood of waterpipe consumption in their population (26).

A ban on waterpipe smoking in the house was inversely associated with current waterpipe smoking. Those who were not allowed to use waterpipe in their houses were less likely to be current users. In some studies, waterpipe consumption by the parents or other family members was a risk factor for children becoming current users (25). Our results demonstrate that exposure to waterpipe smoking in the house, which indicates the current waterpipe use of the family, has a relationship with regular waterpipe consumption by a participant. Waterpipe use should thus be considered seriously by families, particularly parents.

The prevalence of waterpipe consumption in this study was higher than seen in previous studies; it seems that consumption in the Islamic Republic of Iran is increasing. This is not only worrying but also shows the high interest in waterpipe consumption, which could be due to the misperceptions about the safety of waterpipe use. Another notable point of this study is that almost $40 \%$ of waterpipe users also smoke cigarettes. Waterpipe use was about 2 times more likely among cigarette smokers. This is similar to the findings of other studies which have been done in this field $(24,25)$. Considering the methods used in these studies, it cannot be determined whether cigarette use causes the increase in waterpipe use, or vice versa. More comprehensive studies are needed in this regard.

One limitation of this study is that, given its cross-sectional nature, we cannot draw any causal relationship between waterpipe use and different factors. Additionally, data were gathered through filling out questionnaires by the participants themselves, which could result in reporting bias. We tried to control this bias by correcting ambiguous questions, explaining the questions before the start of the survey, and having experts to help the participants during the survey. The study population consists of participants over 15 years old from multiple districts in Tehran. Tehran is the capital of the Islamic Republic of Iran in which different ethnicities live. In order to generalize the results in the whole population of the Islamic Republic of Iran, it would be necessary to do more comprehensive studies, considering locality differences such as urban and rural areas.

The strength of this study lies in its being the first in a general population of the Islamic Republic of Iran to consider waterpipe consumption. Using the WHO standard questionnaire makes the results comparable with other study results. Another strong point in this study is the multi stage cluster sampling based on the municipality and geographical districts of Tehran.

Funding: This project was funded by National Research Institute for Tuberculosis and Lung Diseases.

Competing interests: None declared.

\section{References}

1. Maziak W, Taleb ZB, Bahelah R, Islam F, Jaber R, Auf R, et al. The global epidemiology of waterpipe smoking. Tob control. 2015;24(Suppl. 1):i3-12. PMID:25298368

2. El-Zaatari ZM, Chami HA, Zaatari GS. Health effects associated with waterpipe smoking. Tob Control. 2015;24(Suppl. 1):i31-43. PMID:25661414

3. Aboaziza E, Eissenberg T. Waterpipe tobacco smoking: what is the evidence that it supports nicotine/tobacco dependence? Tob Control. 2015;24(Suppl. 1):i44-53.

4. Jaber R, Madhivanan P, Veledar E, Khader Y, Mzayek F, Maziak W. Waterpipe a gateway to cigarette smoking initiation among adolescents in Irbid, Jordan: a longitudinal study. Int J Tuberc Lung Dis. 2015;19:481-7. PMID:25860006

5. Jawad M, El Kadi L, Mugharbil S, Nakkash R. Waterpipe tobacco smoking legislation and policy enactment: a global analysis. Tob Control. 2015;24(Suppl. 1):i60-5. PMID:25550418
6. Maziak W, Nakkash R, Bahelah R, Husseini A, Fanous N, Eissenberg T. Tobacco in the Arab world: old and new epidemics amidst policy paralysis. Health Policy Plan. 2014;29:784-94. PMID:23958628

7. Akl E, Jawad M, Lam W, Co C, Obeid R, Irani J. Motives, beliefs and attitudes towards waterpipe tobacco smoking: a systematic review. Harm Reduct J. 2013;10(1):12. PMID:23816366

8. Advisory note: waterpipe tobacco smoking: health effects, research needs and recommended actions by regulators. 2nd ed. Geneva: World Health Organization; 2015 (http:// www.who.int/tobacco/publications/prod_regulation/waterpipesecondedition/en/, accessed 2 February 2017).

9. Arrazola RA, Singh T, Corey CG, Husten CG, Neff LJ, Apelberg $\mathrm{BJ}$, et al. Tobacco use among middle and high school.students - United States, 2011-2014. MMWR Morb Mortal Wkly Rep. 2015;64(14):381-5 (http://www.cdc.gov/mmwr/preview/ mmwrhtml/mm6414a3.htm, accessed 2 February 2017). 
10. About GTSS. Atlanta: Centers for Disease Control and Prevention; 2015 (http://www.cdc.gov/tobacco/global/gtss/ (accessed 2 February 2017).

11. Recognize tobacco in its many forms. Silver Spring, Maryland: Food and Drug Administration; 2014 (http://www.fda.gov/forconsumers/consumerupdates/ucm392735.htm\#waterpipes (accessed 2 February 2017).

12. Kelishadi R, Ardalan G, Gheiratmand R, Majdzadeh R, Delavari A, Heshmat R, et al. Smoking behavior and its influencing factors in a national-representative sample of Iranian adolescents: CASPIAN study. Prev Med. 2006;42(6):423-6. PMID:16624397

13. Ghasemian A, Rezaei N, Saeedi Moghaddam S, Mansouri A, Parsaeian M, Delavari A, et al. Tobacco smoking status and the contribution to burden of diseases in Iran, 1990-2010: findings from the Global Burden of Disease Study 2010. Arch Iran Med. 2015 Aug; 18(8):493-501. PMID:26265517

14. WHO report on the global tobacco epidemic, 2008: the MPOWER package. Geneva: World Health Organization; 2008.

15. Sarrafzadegan N, Toghianifar N, Roohafza H, Siadat Z, Mohammadifard N, O'Loughlin J. Lifestyle-related determinants of hookah and cigarette smoking in Iranian adults. J Community Health. 2010;35:36-42. PMID:19866347

16. Baheiraei A, Mirghafourvand M, Nedjat S, Mohammadi E, Mohammad-Alizadeh Charandabi S. Prevalence of water pipe use and its correlates in Iranian women of reproductive age in Tehran: a population-based study. Med Princ Pract. 2012;21:340-4. PMID:22414554

17. Meysamie A, Ghaletaki R, Haghazali M, Asgari F, Rashidi A Khalilzadeh $\mathrm{O}$, et al. Pattern of tobacco use among the Iranian adult population: results of the national Survey of Risk Factors of Non-Communicable Diseases. Tob Control. Apr 2010;19(2):125-8. PMID:20008159

18. Sabahy AR, Divsalar K, Bahreinifar S, Marzban M, Nakhaee N. Waterpipe tobacco use among Iranian university students: correlates and perceived reasons for use. Int J Tuberc Lung Dis. 2011 Jun;15(6):844-7. PMID:21575309

19. Mohammadpoorasl A, Abbasi Ghahramanloo A, Allahverdipour H, Modaresi Esfeh J. Prevalence of hookah smoking in relation to religiosity and familial support in college students of Tabriz, northwest of Iran. J Res Health Sci. 2014;14(4):268-71. PMID:25503281

20. Xuan LTT, Van Minh H, Giang KB, Nga PTQ, Hai PT, Minh NT, et al. Prevalence of waterpipe tobacco smoking among population aged 15 years or older, Vietnam, 2010. Prev Chronic Dis. 2013;10:E57. PMID:23597395

21. Baddoura R, Wehbeh-Chidiac C. Prevalence of tobacco use among the adult Lebanese population. East Mediterr Health J. 2001;7:819-28. PMID:15332785

22. Rahman S, Chang L, Hadgu S, Salinas-Miranda AA, Corvin J. Prevalence, knowledge, and practices of hookah smoking among university students, Florida, 2012. Prev Chronic Dis 2014;11:E214. PMID:25474386

23. Mohammed HR, Zhang Y, Newman IM, Shell DF. Waterpipe smoking in Kuwait. East Mediterr Health J, 2010;16(11):1115-20. PMID:21218733

24. Al-Lawati JA, Muula AS, Hilmi SA, Rudatsikira E. Prevalence and determinants of waterpipe tobacco use among adolescents in Oman. Sultan Qaboos Univ Med J. 2008;8(1):37-43. PMID:21654955

25. Jawad M, Lee JT, Millett C. Waterpipe tobacco smoking prevalence and correlates in 25 Eastern Mediterranean and Eastern European countries: cross-sectional analysis of the Global Youth Tobacco Survey. Nicotine Tob Res. 2016 Apr;18(4):395402. PMID:25957438

26. Poyrazoğlu S, Sarli S, Gencer Z, Günay O. Water pipe (narghile) smoking among medical and non-medical university students in Turkey. Ups J Med Sci. 2010;115(3):210-6. PMID:20636256 